\title{
Effect of Light-Activation with Different Light-Curing Units and Time Intervals on Resin Cement Bond Strength to Intraradicular Dentin
}

\author{
Maria Eleonora MIGUEL-ALMEIDA \\ Mario Lucio da Costa AZEVEDO \\ Fuad Abi RACHED-JÚNIOR \\ Camila Favero OLIVEIRA \\ Ricardo Gariba SILVA \\ Danielle Cristine MESSIAS
}

Dental School, University of Ribeirão Preto, Ribeirão Preto, SP, Brazil

\begin{abstract}
The aim of this study was to assess the bond strength of a resin cement to intraradicular dentin varying the light-curing unit and the moment at which the light was applied. Post spaces of endodontically treated canines were prepared. The roots were distributed into 6 groups $(\mathrm{n}=10)$ according to the light-curing unit and the moment of light exposure: I) Quartz tungsten halogen- $600 \mathrm{~mW} / \mathrm{cm}^{2}(\mathrm{QTH})$ + immediate light activation (t0); II) QTH + light activation after $10 \mathrm{~min}(\mathrm{t} 10)$; III) Light-emitting diodes (LED)-800 $\mathrm{mW} / \mathrm{cm}^{2}$ (LED800)+ t0; IV) LED-800 + t10; V) LED-1,500 mW/cm² (LED-1500)+ t0; VI) LED-1500 + t10. After post cementation, slices from coronal, middle and apical post/root regions were submitted to the push-out test and failure evaluation. It was verified that LED-800 $(4.40 \pm 3.00 \mathrm{MPa})$ and LED-1500 $(4.67 \pm 3.04 \mathrm{MPa})$ provided bond strength statistically superior to QTH $(3.13 \pm 1.76 \mathrm{MPa})(\mathrm{p}<0.05)$, and did not differ from each other $(\mathrm{p}>0.05)$. There was no significant difference between $\mathrm{t} 0$ and $\mathrm{t} 10(\mathrm{p}>0.05)$. Coronal post/root region $(4.75 \pm 3.10 \mathrm{MPa})$ presented significantly higher bond strength than the apical $(3.32 \pm 2.30 \mathrm{MPa})(\mathrm{p}<0.05)$ and middle regions $(4.14 \pm$ $2.99 \mathrm{MPa}$ ) showed intermediate values. Adhesive failures were predominant when using QTH. Adhesive and mixed failures occurred more frequently in the apical region. Higher adhesion of the resin cement to intraradicular dentin was observed in the coronal region with LED light-activation, regardless of the moment of light exposure.
\end{abstract}

Key Words: dental bonding, dental cements, curing lights, dental, dentin.

\section{INTRODUCTION}

The use of intraradicular posts enables rehabilitation of endodontically treated teeth with partially or totally destroyed clinical crown that requires prosthetic or restorative treatment (1).

The retention of glass-fiber-reinforced posts is performed by materials with ability to adhere to dentin. The properties of these materials, such as adhesive systems and resin-based luting agents, and aspects related to the technique and protocol can influence the success of the adhesive cementation of fiber posts (2-4).

Dual-polymerized resin cements are dependent on light-activation to achieve favorable mechanical properties, satisfactory clinical performance $(5,6)$ and to allow for initial stability of the material to resist masticatory stresses (7). It has been speculated that a delay in the light-activation of dual-cured materials would enhance their properties $(7,8)$, as the immediate exposure to light after cement handling could compromise the self-curing reaction by entrapping polymerization promoters and unreacted monomers (6-9).

Assuming that the resin-based luting agents whose self-curing mechanism is deficient or compromised by the immediate light-activation can present changes in their adhesive characteristics (10), the delay in light exposure could favor the chemical reaction, modifying the polymer structure and increasing the degree of conversion $(8,11)$. Consequently, the material's properties could be reinforced by the further conversion 
of monomers by light-activation. Additionally, the degree of conversion and the properties of adhesive cements are influenced by the power density delivered by the curing units $(12,13)$.

Quartz-tungsten halogen (QTH) and light emitting-diodes (LED) are the most commonly employed light-curing units in the clinical practice (14). QTH emits light from a halogen bulb, which is filtered by a dielectric pass-band filter to remove the undesirable wavelengths (14). LED is formed by junctions of doped semiconductors to generate light and requires no filters to produce blue light with a narrow specter (440-490 $\mathrm{nm})$ and falls within the camphoroquinone absorption spectrum $(470 \mathrm{~nm})(15)$.

The impact of light curing-units and delaying the light-activation on bond strength of resin-based luting agents to intraradicular dentin is not well established. The null hypotheses tested in this study were that neither the light-curing unit nor the moment at which the light is applied interferes with the bond strength of resin cement to the root dentin at different post/canal regions. The objective in this study was to assess the push-out bond strength of dual-cured resin cement after light-activation with QTH $600 \mathrm{~mW} / \mathrm{cm}^{2}$, LED $800 \mathrm{~mW} / \mathrm{cm}^{2}$ and LED $1,500 \mathrm{~mW} / \mathrm{cm}^{2}$ immediately or $10 \mathrm{~min}$ after placing the post inside the root canal.

\section{MATERIAL AND METHODS}

This study was independently reviewed and approved by the institutional Ethics Committee.

\section{Specimen Preparation}

Sixty maxillary canines stored in $0.1 \%$ thymol solution at $4{ }^{\circ} \mathrm{C}$ were selected. All teeth had straight roots, completely formed apexes, single canals, no calcification or radiographically confirmed resorption. The teeth were washed in running water for $24 \mathrm{~h}$ to completely remove thymol residues and examined under $\times 20$ stereomicroscope magnification (Leica Microsystems, Wetzlar, Germany) to exclude those with fracture lines or fissures.

The clinical crowns were sectioned transversally close to the cementoenamel junction leaving a root length of $15 \mathrm{~mm}$. The working length was determined by subtracting $1 \mathrm{~mm}$ from the root length using a \#15 K-file. Instrumentation was performed with K3 instruments (SybronEndo Corporation, Glendora, CA,
USA) up to a $\# 40 / .02$ instrument. During this process, root canals were irrigated with $2 \mathrm{~mL}$ of $1 \%$ sodium hypochlorite between each file, followed by final irrigation with $17 \%$ EDTA for 5 min. Final irrigation was done with $10 \mathrm{~mL}$ of distilled water, and the canals were dried with absorbent paper points (Dentsply Ind. e Com. Ltda., Petrópolis, RJ, Brazil). The root canals were filled using thermomechanical condensation with McSpadden instruments (Moyco Union Broach, York, PA, USA), gutta-percha points (Dentsply Ind. e Com., Ltda.) and AH Plus sealer (Dentsply DeTrey, Konstanz, Germany). Radiographs were taken to verify the quality of filling. Specimens were sealed with temporary coronal filling material (Coltosol; Vigodent, Rio de Janeiro, RJ, Brazil) and stored at $37^{\circ} \mathrm{C}$ in relative humidity for $72 \mathrm{~h}$.

\section{Post Space Preparation}

Gutta-percha was initially removed by using heated endodontic pluggers, maintaining at least $4 \mathrm{~mm}$ of filling material in the apical third. Post spaces were prepared to a depth of $10 \mathrm{~mm}$ by using a Largo drill at a low-speed handpiece (Dabi Atlante; Ribeirão Preto, SP, Brazil). Final irrigation was done with distilled water and the post spaces were dried with paper points.

\section{Post Cementation}

Parallel glass fiber-reinforced composite posts (Reforpost\#3; Angelus, Londrina, PR, Brazil) were used.

For the adhesive luting procedure, a bonding agent (ED Primer II; Kuraray, Tokyo, Japan) was applied inside the root canal as well as onto the posts for $30 \mathrm{~s}$. The adhesive was gently air dried and the excess material was removed with paper points. The pre-treated posts were coated with the resin luting agent (Panavia F 2.0; Kuraray) and immediately seated into the root canals.

The specimens were randomly distributed into 6 groups ( $\mathrm{n}=10$ ) according to the light-curing unit and the moment at which light was applied: I) quartz-tungsten halogen $(\mathrm{QTH})$ with $600 \mathrm{~mW} / \mathrm{cm}^{2}$ power density (Ultralux; Dabi Atlante) + immediate light-activation (t0); II) QTH + light-activation after 10 min (t10); III) LED with $800 \mathrm{~mW} / \mathrm{cm}^{2}$ power density (Spaceled; Ecel, RibeirãoPreto, SP, Brazil) (LED-800) + t0; IV) LED$800+\mathrm{t} 10 ; \mathrm{V})$ LED with $1,500 \mathrm{~mW} / \mathrm{cm}^{2}$ power density (Radii Plus; SDI Ltd, Bayswater, Victoria, Australia) $($ LED-1500) + t0; VI) LED-1500 + t10 .

Excess material was removed and the resin luting 
agent was light-cured with the allocated light-curing unit at the determined moment by placing the light tip perpendicularly to the post for $40 \mathrm{~s}$. The light-tip distance was standardized as being the coronal remaining portion of the post. Before each luting procedure, the light output of each curing unit was measured with a light curing meter (Ecel) to ensure accurate light intensity.

\section{Push-out Test}

The specimens were serially sectioned horizontally using a precision cutting machine (Isomet 1000, Buehler, Hong Kong, China) with water cooling. Post/dentin sections with $1 \mathrm{~mm}$ thickness were obtained from each coronal, middle and apical regions and subjected to the push-out test. Each section was marked on its apical side and fixed in a stainless steel base, with a central hole attached to the lower portion of a universal testing machine (Instron Model 4444; Instron, Canton, MA, USA). The specimen was positioned in the machine, ensuring that the coronal surface faced the metallic base and the resin/cement/post was centered over the hole in the base. The push-out test was performed by applying a compressive load to the apical aspect of each slice by using a 0.6 - $\mathrm{mm}$-diameter cylindrical plunger attached to the upper portion of the Instron machine. A crosshead speed of $0.5 \mathrm{~mm} / \mathrm{min}$ was applied until bond failure occurred. To express the bond strength in $\mathrm{MPa}$, the load at failure recorded in $\mathrm{N}$ was divided by the area $\left(\mathrm{mm}^{2}\right)$ of the post/dentin interface.

After the push-out test, the fragments were examined under $\times 20$ stereomicroscope magnification (Leica Microsytem LTD) to assess the failure mode, which was considered adhesive (when occurred in the dentin/adhesive cement interface), cohesive (when the rupture occurred in the cement), and mixed (when both modes were combined).

\section{Statistical Analysis}

After checking the assumption of homogeneity of variance and normal distribution, bond strength data were analyzed statistically by ANOVA with a significance level of 5\%. Tukey's test was applied where significant differences were detected. The SPSS 17 software (SPSS Inc., Chicago, IL, USA) was used to perform the statistical analyses.

\section{RESULTS}

There was a statistically significant effect for the factors light-curing units $(\mathrm{p}=0.003)$ and post/canal region $(\mathrm{p}=0.011)$. Neither the immediate or delayed light-activation $(\mathrm{p}=0.057)$ nor the interaction among the factors $(\mathrm{p}=0.44)$ had significant effect.

QTH provided the lowest bond strength values $(3.13 \pm 1.76)$ and differed significantly from LED-800 $(4.40 \pm 3.00)$ and LED-1500 (4.67 \pm 3.04$)(p<0.05)$, which did not differ from each other $(\mathrm{p}>0.05)$.

For the post/canal region, the coronal region presented higher bond strength values $(4.75 \pm 3.10)$ of the adhesive luting system to the dentin, and it was statistically different from the apical region $(3.32 \pm$ 2.30) $(\mathrm{p}<0.05)$. The middle region $(4.14 \pm 2.99) \mathrm{had}$ intermediate values that were not statistically different from both the coronal and apical regions.

In the failure analysis, prevalence of adhesive failures was observed in the group light-activated with QTH, regardless of the post/canal region and the moment at which the light was applied. For the group LED-800, there was predominance of mixed failures in the coronal and middle regions and adhesive in the apical region, regardless of the moment of light exposure. It was also verified that the immediate light-activation with LED-

Table 1. Failure modes observed in each group after the push-out test (\%).

\begin{tabular}{|c|c|c|c|c|c|c|c|c|c|c|c|c|c|c|c|c|c|c|}
\hline \multirow{3}{*}{$\begin{array}{l}\text { Failure } \\
\text { mode }\end{array}$} & \multicolumn{6}{|c|}{ QTH } & \multicolumn{6}{|c|}{ LED - 800} & \multicolumn{6}{|c|}{ LED - 1500} \\
\hline & \multicolumn{3}{|c|}{ Immediate } & \multicolumn{3}{|c|}{ After $10 \mathrm{~min}$} & \multicolumn{3}{|c|}{ Immediate } & \multicolumn{3}{|c|}{ After $10 \mathrm{~min}$} & \multicolumn{3}{|c|}{ Immediate } & \multicolumn{3}{|c|}{ After $10 \mathrm{~min}$} \\
\hline & $\mathrm{C}$ & M & A & $\mathrm{C}$ & $\mathrm{M}$ & A & $\mathrm{C}$ & M & A & $\mathrm{C}$ & M & A & $\mathrm{C}$ & M & A & $\mathrm{C}$ & $\mathrm{M}$ & A \\
\hline Adhesive & 50 & 60 & 70 & 60 & 60 & 80 & 10 & 20 & 60 & 20 & 30 & 60 & 0 & 10 & 40 & 10 & 10 & 50 \\
\hline Cohesive & 30 & 0 & 0 & 20 & 10 & 0 & 30 & 30 & 0 & 0 & 0 & 0 & 50 & 50 & 10 & 50 & 30 & 10 \\
\hline Mixed & 20 & 40 & 30 & 20 & 30 & 20 & 60 & 50 & 40 & 80 & 70 & 40 & 50 & 40 & 50 & 40 & 60 & 40 \\
\hline
\end{tabular}

C: coronal post/canal region; M: middle post/canal region; A: apical post/canal region. 
1500 presented a higher amount of cohesive and mixed failures in the coronal region, cohesive in the middle, and mixed in the apical region. When the adhesive cement was light-activated after $10 \mathrm{~min}$, cohesive failures were predominant in the coronal region, mixed failures in the middle third and adhesive failures in the apical post/canal region. The percentage of failures is given in Table 1 .

\section{DISCUSSION}

The null hypotheses were partially not accepted since only light curing-units affected the bond strength of resin-based luting agents to the intraradicular dentin.

The results of the present study revealed that the light-activation with QTH light-curing unit provided lower bond strength of the resin-based luting agents to the intraradicular dentin than LEDs. Although the bond strength values cannot be used as predictors of the degree of conversion of monomers into polymers, the findings of this study suggest an adequate monomer conversion after light-activation with LED, as verified by Carvalho et al. (16). This is probably due to the higher power density $(12,13)$ of the LED unit used in this investigation, which may have favored a more effective cure of the resin-based material (13). The prevalence of adhesive failures in the QTH light-activated group is in agreement with the lower bond strength. An adequate degree of conversion implies absence or reduced residual monomers(16), which decreases the occurrence of porosities (17) and may contribute to limit the loss of adhesion observed in this study. In this sense, light-curing units of high intensity could be employed to achieve efficient polymerization of resin materials, especially in deep cavities (15).

Conversely, the push-out bond strength of the adhesive cement was not influenced by the immediate and delayed light-activation. Faria-e-Silva et al. (18) found that the Panavia F did not present any significant polymerization reaction for $5 \mathrm{~min}$, suggesting low concentration of initiators of chemical reaction. This fact could also justify the lack of difference in the adhesion of the resin cement light-activated immediately or after 10 min. Delaying light-activation did not benefit the chemically activated reaction and did not influence the bond strength of cement to the root dentin. Considering that immediate exposure to the light commonly occurs in the clinical practice, it seems that there is no justification for adopting the delayed curing protocol, as no difference was found to the immediate activation.
Although the chemical reaction may not have been achieved immediately after cement manipulation and within $10 \mathrm{~min}$, this might have occurred later. In this context, it is assumed that the appropriate moment to perform the light-activation varies with the activation potential of the resin-based cement (14). Materials with high potential for chemical reaction can reach appropriate degree of conversion delaying the lightactivation for the chemical reaction to take place (14). For dual-cured resin cements with high photoinitiator concentration, the immediate light-activation may be preferable (14), which may be the case of the cement used in this study.

When the bond strength was compared among the post/canal regions, the findings showed that the coronal region was superior to the apical region and that the middle region did not differ from the others. Unlike Yoldas and Alaçan (19), who found that the polymerization of resin material has occurred at a $15 \mathrm{~mm}$ depth, the present results suggest that the polymerization of cement was compromised in the apical region, where the light has a reduced range. The differences among post/canal regions can be explained by the regional differences in the root dentin such as quantity, volume and orientation of the tubules toward the apical portion, apical sclerosis (20), the high cavity configuration factor, the difficulty in visualization and access to this region, restrictions in the flow and distribution of material in the apical region that makes more bubbles and voids within the cement (21) and presence of smear layer formed during the post space preparation, which could not be modified by the adhesive cement or removed by irrigation with sodium hypochlorite and EDTA (22). Another aspect to be considered is the limited light transmission capability of the fiber post used in the present study (22), with impaired polymerization of cement and bonding quality in the apical portion $(5,22)$.

Despite the methodological differences, previous studies $(2,3,20,22-24)$ have also verified higher bond strength in the coronal root canal region. Analysis of the failure modes confirm the lower values of adhesion in the apical region, with predominance of adhesive and mixed-type failures in this region.

In the present study, LED units with 800 and $1,500 \mathrm{~mW} / \mathrm{cm} 2$ power densities provided higher bond strength of the resin cement to the root canal than QTH. Conversely, light activation performed immediately or after $10 \mathrm{~min}$ did not affect the bond strength between the resin cement and the root dentin. The coronal post/ 
canal region presented higher bond strength than the apical region.

\section{RESUMO}

O objetivo deste estudo foi avaliar a resistência de união do cimento resinoso à dentina intrarradicular em função da fonte fotoativadora e do momento de aplicação da luz. Os espaços para cimentação dos pinos foram preparados em caninos tratados endodonticamente. As raízes foram distribuídas em seis grupos ( $\mathrm{n}$ $=10$ ) de acordo com a fonte fotoativadora e momento de exposição à luz: I) Luz halógena (LH) com densidade de potência $600 \mathrm{~mW} /$ $\mathrm{cm}^{2}+$ fotoativação imediata (t0); II) LH + fotoativação após $10 \mathrm{~min}$ (t10); III) LED com densidade de potência $800 \mathrm{~mW} / \mathrm{cm}^{2}$ (LED800)+ t0; IV) LED-800 + t10; V) LED com densidade de potência $1.500 \mathrm{~mW} / \mathrm{cm}^{2}$ (LED-1500)+ t0; VI) LED-1500 + t10. Após a cimentação dos pinos, slicesdas regiões cervical, média e apical foram submetidos ao teste de push-out e avaliação das falhas. Verificou-se que LED-800 (4,40 $\pm 3,00 \mathrm{MPa})$ e LED-1500 (4,67 $\pm 3,04 \mathrm{MPa}$ ) proporcionaram resistência de união estatisticamente superior à $\mathrm{LH}(3,13 \pm 1,76 \mathrm{MPa})(\mathrm{p}<0,05)$, e não diferiram entre si $(\mathrm{p}>0,05)$.Não houve diferença estatisticamente significante da resistência de união entre t0 e t10 $(p>0,05)$. A região cervical $(4,75 \pm 3,10 \mathrm{MPa})$ apresentou maiores valores de resistência de união que a apical $(3,32 \pm 2,30 \mathrm{MPa})(\mathrm{p}<0,05)$ e a região média $(4,14 \pm 2,60 \mathrm{MPa})$ mostrou valores intermediários. Falhas adesivas foram predominantes no grupo $\mathrm{LH}$, independentemente da região pino/canal. A parte apical apresentou predomínio de falhas adesivas e mistas. Concluiu-se que a resistência de união do cimento resinoso à dentina intrarradicular foi maior no terço cervical,com fotoativação com LED, independente do momento de exposição à luz.

\section{REFERENCES}

1. Cagidiaco MC, Goracci C, Garcia-Godoy F. Clinical studies of fiber posts: A literature review. Int J Prosthodont 2008;21:328-336.

2. Goracci C, Tavares AU, Fabienelli A, Monticelli F, Rafaelli O, Cardoso PC, et al.. The adhesion between fiber posts and root canal walls: comparison between microtensile and push-out bond strength measurements. Eur J Oral Sci 2004;112:353-361.

3. De Durão-Mauricio PJ, Gonzalez-Lopez S, Aguilar-Mendonza JA, Felix S, Gonzalez-Rodriguez MP. Comparison of regional bond strength in root thirds among fiber reinforced posts luted with different cements. J Biomed Mater Res B Appl Biomater 2007;83:364-372.

4. Mallmann A, Jacques LB, Valandro LF, Muench A. Microtensile Bond strength of photoactivated and autopolymerized adhesive systems to root dentin using translucent and opaque fiberreinforced composite posts. J Prosthet Dent 2007;97:165-172.

5. Faria-e-Silva AL, Arias VG, Soares LE, Martins AA, Martins LR. Influence of fiber post translucency on the degree of conversion of a dual-cured resin cement. J Endod 2007;33:303-305.

6. Moraes RR, Brandt WC, Naves LZ, Correr-Sobrinho L, Piva E. Light- and time-dependent polymerization of dual-cured resin luting agent beneath ceramic. Acta Odontol Scand 2008;66:257261.

7. Pegoraro TA, da Silva NR, Carvalho RM. Cements for use in esthetic dentistry. Dent Clin North Am 2007;51:453-471.

8. Faria-e-Silva A, Boaro L, Braga R, Piva E, Arias V, Martins L Effect of immediate or delayed light activation on curing kinetics and shrinkage stress of dual-cure resin cements. Oper Dent 2011;36:196-204.

9. Moraes RR, Faria-Silva AL, Ogliari FA, Correr-Sobrinho L, Demarco FF, Piva E. Impact of immediate and delayed light activation on self-polymerization of dual-cured dental resin luting agents. Acta Biomater 2009;5:2095-2100.

10. Arrais CAG, Giannini M, Rueggeberg FA, Pashley DH. Effect of curing mode on microtensile bond strength to dentin of two dualcured adhesive systems in combination with resin luting cements for indirect restorations. Oper Dent 2007;32:37-44.

11. Kournetas N, Tzoutzas I, Eliades G. Monomer conversion in dual cured core buildup materials. Oper Dent 2011;36:92-97.

12. Halvorson RH, Erickson RL, Davidson CL. An energy conversion relationship predictive of conversion profiles and depth of cure for resin-base composites. Oper Dent 2003;28:307-314.

13. Gaglianone LA, Lima AF, Araújo LS, Cavalcanti AN, Marchi GM. Influence of different shades and LED irradiance on the degree of conversion of composite resins. Braz Oral Res 2012;26:165-169.

14. Reges RV, Costa AR, Correr AB, Piva E, Puppin-Rontani RM, Sinhoretti MA, et al.. Effect of light-curing units, post-cured time and shade of resin cement on Knoop hardness. Braz Dent J 2009;20:410-413.

15. Santos GC, El-Mowafy O, Rubo JH, Santos MJ. Hardening of dual-cure resin cements and a resin composite restorative cured with QTH and LED curing units. J Can Dent Assoc 2004;70:323328.

16. Carvalho FA, Almeida RC, Almeida MA, Cevidanes LH, Leite MC. Efficiency of light-emitting diode and halogen units in reducing residual monomers. Am J Orthod Dentofacial Orthop 2010;138:617-622.

17. Ferracane JL. Elution of leachable components from composites. J Oral Rehabil 1994;21:441-452.

18. Faria-e-Silva AL, Fabião MM, Arias VG, Martins LR. Activation mode effects on the shear bond strength of dual-cured resin cements. Oper Dent 2010;35:515-521.

19. Yoldas O, Alaçam T. Microhardness of composites in simulated root canals cured with light transmitting posts and glass-fiber reinforced composite posts. J Endod 2005;31:104-106.

20. Onay EO, Korkmaz Y, Kiremitci A. Effect of adhesive system type and root region on the push-out bond strength of glass-fiber posts to radicular dentin. Int End J 2010;43:259-268.

21. Bolhuis P, de Gee A, Feilzer A. The influence of fatigue loading on the quality of the cement layer and retention strength of carbon fiber post-resin composite core restorations. Oper Dent 2005;30:220-227.

22. Zorba YO, Erdemir A, Turkylmaz A, Eldeniz AU. Effects of different curing-units and luting agents on push-out bond strength of translucent posts. J Endod 2010;36:1521-1525.

23. Akgungor G, Akkayan B. Influence of dentin bonding agents and polymerization modes on the bond strength between translucent fiber posts and three dentin regions within a post space. J Prosthet Dent 2006;95:368-378.

24. Kalkan M, Usumez A, Ozturk AN, Bellis S, Eskitascioglu G. Bond strength between root dentin and three glass-fiber post system. J Prosthet Dent 2006;96:41-46.

Received May 15, 2012 Accepted September 20, 2012 